\title{
O poema lírico: entre rupturas e permanências
}

\author{
The lyric poem: between ruptures and permanences
}

\author{
Naiana Pereira de Freitas* \\ Universidade Federal da Babia \\ Salvador, Babia, Brasil \\ Nancy Rita Ferreira Vieira* \\ Universidade Federal da Babia \\ Salvador, Babia, Brasil
}

\begin{abstract}
Resumo: O poema, diante da tradição e das vanguardas literárias, extraiu os elementos necessários para manterse "vivo" até os dias atuais. Esta sobrevivência evidencia que a ação de transformar a poesia não dominou apenas o período moderno assinalado por Hugo Friedrich (1978), mas sim, avançou para a poesia posterior, a contemporânea. Neste cenário, a poetisa baiana Ângela Vilma inclui-se em uma investigação que, em alguma medida, recupera a tensão entre o "velho" e o "novo". Essa relação diz respeito aos modos de produção e publicação da poesia lírica no mercado editorial, visto que, na contemporaneidade, este circuito foi alterado pela inserção das novas tecnologias como o blog. A fim de desenvolver a discussão proposta faz-se necessário recorrer teorizações anteriores desenvolvidas por alguns pesquisadores como Walter Benjamim (1989), Salete Cara (1989), Karl Erik Schollhammer (2009), Octavio Paz (2012), Marjorie Perloff (2013) entre outros.
\end{abstract}

Palavras- Chave: Poema lírico. Literatura baiana. Ângela Vilma.

Abstract: The poem, before the tradition and the literary vanguards, extracted the necessary elements to remain "alive" until the present day. This survival evidences that the action of transforming poetry did not dominate only the modern period pointed out by Hugo Friedrich (1978), but rather, advanced to the later, contemporary poetry. In this scenario, the Bahian poet Ângela Vilma is included in an investigation that to recovers the tension between the "old" and the "new." This relationship concerns the modes of production and publication of lyrical poetry in the publishing market, in contemporary times, this modes of production was altered by the insertion of new technologies, as the blog. In order to develop the proposed discussion, it is necessary to use to previous theories developed by some researchers such as Walter Benjamim (1989), Salete Cara (1989), Karl Erik Schollhammer (2009), Octavio Paz (2012), Marjorie Perloff (2013) others.

Keywords: Lyric poem. Bahia Literature. Ângela Vilma.

\section{INTRODUÇÃO}

A partir da afirmativa de Hugo Friedrich, no texto A perspectiva da lírica contemporânea: dissonâncias e anormalidade (1978), iniciaremos a breve discussão pretendida neste trabalho. De acordo com este teórico, “[...] Das três maneiras possíveis de comportamento da composição lírica - sentir, observar, transformar - é esta última que

\footnotetext{
* Estudante de Doutorado do Programa de Pós-graduação de Literatura e Cultura da Universidade Federal da Bahia. E-mail: Naiana freitas@hotmail.com

* Professora Doutora da Universidade Federal da Bahia. (Orientadora).E-mail: nancyrfv@gmail.com
} 
domina na poesia moderna e, em verdade, tanto no que diz respeito ao mundo como a língua.” (FRIEDRICH,1978, p.17). É necessário destacar desta afirmação o termo "transformar", pois dele extrairemos o fio condutor que permitirá desenvolver a argumentação em torno da questão que este artigo pretende responder: em que medida a lírica moderna se afasta e/ou se aproxima da lírica contemporânea?

Para Friedrich (1978), a transformação caracterizava-se como um movimento preponderante para a definição da poesia moderna, pois tornou possível uma noção de sujeito lírico concebido para além do estado anímico do poeta, contrastando assim, com a tradição romântica, que postulava o recurso da emotividade como elemento essencial para distinguir este gênero literário. Se, ampliarmos a leitura desta afirmação para épocas posteriores, ou até anteriores como na Grécia antiga, perceberemos como o gênero lírico não cessou de seguir um curso a caminho de alterações, e simultaneamente permaneceu com traços específicos, em sua composição, que remetem a parâmetros seculares. Neste sentido, ouso arriscar, que a tensão entre rupturas e permanências dentro do gênero é o ingrediente para garantir o combustível necessário para a combustão ininterrupta do incêndio, chamado poema.

O poema diante da tradição e das vanguardas literárias extraiu os elementos necessários para manter-se de pé em épocas sucessivas, em meio aos fatores como público leitor, crítica especializada, mercado editorial e poetas. Evidenciando que, a ação de transformar não dominou apenas o período moderno assinalado pelo teórico, mas sim avançou para a poesia posterior, a contemporânea. A partir desta linha de raciocínio pretendemos refletir acerca da constituição da modernidade e seus desdobramentos na literatura, a seguir, abordaremos a lírica no período contemporâneo, neste cenário, procuraremos incluir brevemente a poetisa baiana Ângela Vilma, em uma investigação que, em alguma medida, recupere a tensão entre o "velho" e o "novo". Essa relação diz respeito aos modos de produção e publicação da poesia lírica no mercado editorial, visto que, na contemporaneidade, este circuito foi alterado pela inserção das novas tecnologias como o blog 1 .

\section{A REALIZAÇÃO LÍRICA NA GRÉCIA ANTIGA}

Antes de iniciarmos a discussão em torno da modernidade é importante realizar uma breve digressão acerca da composição lírica produzida na antiguidade. Segundo Salete Cara (1989), na Grécia antiga, origina-se o texto lírico porque havia a necessidade de manifestar um "eu" que absorvesse o momento sociocultural vivido pela população da

\footnotetext{
${ }^{1}$ Ângela Vilma graduou-se em Letras Vernáculas pela Universidade Estadual de Feira de Santana (1998), concluiu o mestrado e o doutorado em Teoria da Literatura pela Universidade Federal de Pernambuco em 2001 e 2006 respectivamente. Desde 2010, leciona em regime de dedicação exclusiva na Universidade Federal do Recôncavo da Bahia, na cidade de Amargosa/BA. Como escritora já publicou livros de poesia e contos no mercado editorial baiano tanto em obras individuais como em coletâneas como, por exemplo, Beira-vida (1990); Poemas escritos na pedra (1994); A casa (1997); Ela, João e o Terno (1998); Poemas para Antônio (2010). E fez parte das coletâneas: Sete Faces (1996), Figuras contínuas (2000), Concerto lírico a quinze vozes (2005) e Tanta Poesia (2006). A escritora mantém o blog Aeronauta, desde 2007.
} 
Pólis. Nesta época, as relações entre o Estado e os cidadãos complicavam-se devido ao excesso de burocracia. A escrita lírica torna-se oposta ao modelo dos textos épicos, pois enquanto no primeiro o "eu" anunciado possui características individuais, no segundo a mensagem é voltada para a coletividade. É a partir do estudo produzido por Aristóteles, que a poesia lírica assume cada vez mais características que a afastam dos outros gêneros, como o épico e o dramático. Conforme afirma Salvatore D`onofrio (1995) no texto Teoria do Texto 2 - teoria da lírica e do drama ${ }^{2}$, "[...]Aristóteles distingue a poesia mélica ou lírica, que era a palavra "cantada", da poesia épica ou narrativa, que era a palavra recitada", e da poesia dramática, que era a palavra "representada".

A poesia grega antiga estava inserida no contexto social da Pólis e por meio dela os ensinamentos eram transmitidos para os cidadãos, cerimônias religiosas eram realizadas, ou seja, esta poesia possuía contornos que iam além da simples distração do público. Neste sentido, o "eu" cantado necessitava de um direcionamento voltado para o cumprimento de uma função pedagógica e ritualística defendido pelos gregos. Nas palavras de Roosevelt Rocha (2012, p.94),

[...] a poesia grega arcaica tem um caráter pragmático, pois ela estava ancorada na realidade dos fenômenos. Ela recorre habitualmente ao mito como narrativa de caráter religioso e como paradigma positivo ou negativo. [...] Ela tinha função educativa, civilizatória. Sua execução oral se dava diante de um auditório e era realizada por um indivíduo ou por um grupo de pessoas com acompanhamento de um ou mais de um instrumento musical. [...]Ela era fictio, inventio, processo criativo em que se usava a imaginação, mas sempre conservando sua ligação com a realidade vivida, experimentada pelo poeta.

A poesia lírica grega operava em um circuito de recepção, elaboração e de visão de mundo que gradualmente vai se alterando em épocas posteriores. A lírica grega representava o ritmo harmônico do universo, e uma relação de consonância do poeta com esta conjuntura. Como é ressaltado por Roosevelt Rocha (2012), a poesia grega trazia em seu cerne elementos que refletiam a necessidade de criatividade do autor com a finalidade de garantir uma elaboração lírica ancorada na noção de arte que defendiam, bem como, uma espécie de relação obrigatória entre a "[...] a realidade vivida, experimentada pelo poeta. (ROCHA, 2012, p.94) e a sua produção. A partir deste ponto, faremos uma breve incursão no modelo de sujeito lírico presente no Romantismo, período posterior que foi importante para a (re)formulação das bases teóricas para o estudo literário.

\section{O MODELO DE SUJEITO LÍRICO NO ROMANTISMO}

De acordo com Eloá Hebe e Ruth Röhl (1986), em meados do século XVIII, surge na Alemanha o movimento Sturm und Drang (Tempestade e ímpeto) iniciando o que conhecemos como Romantismo. Os participantes deste movimento pregavam a valorização do sentimento, liberdade e genialidade. Seus pressupostos iam contra as duas correntes de pensamento, que fundamentavam o Iluminismo, o Racionalismo (França) e

${ }^{2}$ Livro online sem paginação. 
Empirismo (Inglaterra). Os dois escritores alemães que encabeçavam este movimento são: Goethe e Schiller. O Romantismo Alemão surgido com o Sturm und Drang, trazia como marca a presença de diferentes tendências. As duas vertentes principais desta Escola estavam localizadas nas cidades de Jena e Heidelberg.

Em leitura a Friedrich Schlegel, maior representante da crítica ao Romantismo Alemão, as autoras Eloá Hebe e Ruth Röhl (1986) apontam três fatores que propiciaram o surgimento da Escola romântica na Alemanha. São eles: a Revolução Francesa, a filosofia de Fichte, o romance de Goethe, Os anos de aprendizado de Wilhelm Meister. Interessa-nos para a discussão neste trabalho, a influência da filosofia de Johan Gottlieb Fichte nos escritores deste período. Este filósofo desenvolve a concepção de Eu como princípio básico de ordenação do mundo objetivo, sendo portanto um Eu incondicional e criador. Para as autoras, “[...] o idealismo subjetivo de Fichte vai influenciar os românticos em seu conceito de autonomia da criação literária.” (HEBE; RÖHL, 1986, p.43)

Para os alemães a poesia lírica para existir necessitava assumir seu caráter preponderantemente subjetivo. Os poetas românticos assumem a ênfase no "eu" como uma forma de reagir ao excesso de racionalismo presente neste período histórico. Nesta perspectiva, negam o presente e se abrigam no passado, e principalmente enceram-se em si, representando a sua subjetividade. Para Dominique Combe (2008-2009) "[...]Nessas condições, "o centro e o conteúdo próprio da poesia lírica é o sujeito poético concreto, em outras palavras, o poeta"” (COMBE,2008-2009, p.115).

O contexto histórico na Europa durante as últimas décadas do século XVII e até a metade do século XIX favoreceu a revolução promovida pelos românticos. Neste cenário, o movimento romântico lança as bases estéticas que influenciariam decisivamente as produções literárias subsequentes, além de contribuir para a formulação de noções, como a de gênio original. Esta linha de raciocínio, enquadra-se com a "autonomia do intelecto" defendida pelos os artistas do Romantismo. Segundo Jair Ramos Braga Filho (2006, p.16),

Rompendo os antigos elos sociais, os românticos, após o desligamento com a ordem divina e com a hierarquia eclesiástica e secular que pregavam a absoluta nulidade do espírito, tornam concebível a ideia de autonomia intelectual. O indivíduo era estimulado a revoltar-se contra todas as amarras sociais entre ele e sua felicidade. Assim, o romântico considerava a vida de acordo com critérios da arte, elevando-se acima dos outros homens. É o germe do conceito de gênio romântico.

Em consequência desta postura, frente ao mundo, os poetas românticos negam o pensamento corrente, até então, de que a literatura é apenas a imitação da natureza, enfatizando que o escritor é o sujeito capaz de elaborar diferentes realidades a partir de sua elaboração criativa, ou melhor genialidade. O poeta torna-se Deus de sua obra, único responsável por sua arte. Portanto, os participantes do Romantismo iniciam, talvez despercebidamente, o movimento de crise do sujeito, pois a partir de sua liberdade criativa podem projetar, por meio da ironia, a crítica a sociedade, bem como a independência intelectual. 


\section{A REALIZAÇÃO LÍRICA NA MODERNIDADE}

A modernidade foi um período marcado por um profundo processo de urbanização e mecanização que resultou em alterações em várias frentes, como nas instituições políticas, econômicas, ideológicas e também nas formulações da arte em geral. Conforme Antony Guiddens (1991), "[...]Os modos de vida produzidos pela modernidade nos desvencilharam de todos os tipos tradicionais de ordem social, de uma maneira que não tem precedentes." (GIDDENS, 1991, p.10). Este teórico elenca algumas características que confirmam este estado de espírito da era moderna, como por exemplo, ritmo de transformação no campo tecnológico, intenção da mudança, que passa a percorrer todo o globo através de um processo de interconexão e por fim, as alterações na natureza das instituições políticas, como o surgimento do Estado-Nação. Neste cenário, o artista moderno procurará por meio da experimentação da linguagem encontrar o sentido para a existência humana.

É importante destacar, que os modernos instituíram algumas rupturas estéticas com a tradição romântica, entretanto, souberam reconhecer as contribuições implementadas por esta Escola. Com a finalidade de mapear os elementos constitutivos da lírica moderna (a partir da segunda metade do século XIX), Hugo Friedrich em seu clássico texto A perspectiva da lírica contemporânea: dissonâncias e anormalidade (1978), põe lado a lado a lírica produzida pelos poetas românticos e modernos com o objetivo de elucidar as noções presentes na lírica moderna. Para este autor, o artista moderno,

[...] não mais participa em sua criação como pessoa particular, porém como inteligência que poetiza, como operador da língua, como artista que experimenta os atos de transformação de sua fantasia imperiosa ou de seu mundo irreal de ver um assunto qualquer, pobre de significado em si mesmo. Isto não exclui que tal poesia nasça da magia da alma e a desperte. Mas trata-se de algo diferente de estado de ânimo. (FRIEDRICH, 1978, p.17)

O poeta moderno assume, nesta perspectiva, duas características: "inteligência que poetiza", e o "operador da língua", que permitem um afastamento entre a lírica moderna e a romântica. Não uma negação por completo, pois a "inteligência que poetiza" é, em nossa opinião, o grau máximo da vazão a autonomia intelectual surgida na poesia lírica romântica, com o acréscimo de uma nova concepção de genialidade não encontrada no íntimo do poeta, mas em seu trabalho com a linguagem. Neste sentido, a ênfase na "inteligência que poetiza" e não mais no "estado de ânimo do poeta", apresenta-se como um fator relevante para o estabelecimento da transformação dos pressupostos da lírica na época moderna.

A noção de sujeito lírico na modernidade pouco a pouco ganha uma nova perspectiva, esvaziando aquela unidade entre o poeta, vida e obra. Entretanto, isto não quer dizer que modos de realização lírica centrados na subjetividade transbordante do poeta tenham desaparecido, afirmar isto pressuporia pensar que a engrenagem que dirige qualquer sociedade está pautada em uma homogeneidade de ações, pensamento inconcebível após os estudos promovidos pelos pós-estruturalistas. 
A partir de meados do século XIX, o poeta torna-se mais consciente de sua "autonomia intelectual", ou seja, o seu fazer poético não é resultado de seu estado de ânimo, nem do canto da inspiração. Na poesia moderna ocorre a fratura entre o poeta, a subjetividade e o mundo exterior. Para Friedrich, a poesia nascida durante este período carece de uma "intimidade comunicativa" (FRIEDRICH, 1978, p.17), que foi utilizada extensamente pelos poetas românticos.

Seguindo a linha de raciocínio de Hugo Friedrich (1978), observamos um elenco de características recorrentes na poesia moderna, dentro de uma investigação centrada em um corpus específico. Se a crítica contemporânea, como o texto A verdade da poesia de Michael de Hamburg, aponta diversas falhas neste texto clássico, deve-se também, a uma leitura que não leva em conta o período em que o texto foi formulado. Deixando de lado estas ressalvas, retornemos aos pensamentos de Hugo Friedrich. Para este teórico, o poema produzido neste período continha características como: "obscuridade intencional", "incompreensibilidade", "significação pluriforme" e por fim uma "tensão dissonante" (FRIEDRICH, 1978). Por hora, discutiremos as duas últimas características finais, por acreditar que em alguma medida elas se presentificam na poesia contemporânea.

Para Octavio Paz (2012, p.37), “[...] Todo o período de crise se inicia ou coincide com a crítica da linguagem" podemos pensar a partir desta afirmativa, como o poeta moderno, ou melhor o artista moderno reflete em sua criação artística o profundo sentimento de desagregação promovido pelo processo de transformação tecnológico, cientifico evidenciado na modernidade. A fim de ilustração, podemos citar o estudo realizado por Walter Benjamim, no texto O Flâneur (1989) acerca de dois personagens, o flâneur e o basbaque, presentes nas cidades modernas. E, como estas figuras em alguma medida são evocadas em alguns poemas do poeta brasileiro do século XX, Carlos Drummond de Andrade.

O Flâneur é uma personagem que observa o nascimento da cidade moderna. A atmosfera urbana requer uma nova postura de seus habitantes diante das situações. É interessante observar como Walter Benjamim afirmou sua teoria através do uso de fragmentos literários. Nesses registros, as cidades da Europa vão modelando-se a urbanização. A rua já cimentada recebe os novos meios de transporte abarrotados de pessoas que se locomovem de lá para cá. O espaço urbano é moldado pela multidão que traz como característica comum em seus participantes a solidão e a individualidade.

O poeta assume ao mesmo tempo todas as personas instaladas na figura do Flâneur e Basbaque. Ele é detetive, jornalista, observador, ocioso, duvida e sente as impressões diante dos acontecimentos. O observador Benjaminiano é alguém que observa e analisa, caso contrário, à figura do flâneur não encarnaria a representação do detetive. Por outro lado, a solidão que compõe o andarilho da cidade na Europa do século XIX é amplamente irradiada nos poemas de Carlos Drummond de Andrade. Enquanto Hugo Friedrich toma exemplos da literatura europeia para teorizar a sua fundamentação sobre a realização lírica moderna, neste texto, recorremos a este poeta que dialoga com os princípios que nortearam o alvorecer da sociedade moderna na Europa. 
No poema "A bruxa”, de Carlos Drummond de Andrade, podemos perceber a "dialética da flânerie" (BENJAMIM, 1989, p.190), apontada por Benjamim, no seguinte trecho: “[...] Estou cercado de olhos, /de mãos, afetos, procuras./Mas se tento comunicar-me,/o que há é apenas a noite/e uma espantosa solidão.” (DRUMMOND, 1998, p.74). A ação de observar a cidade permite a aproximação com pessoas, pois o poeta a fim de colher elementos para sua escrita precisa frequentar a urbanidade. $\mathrm{O}$ contato com a vida fora de casa promove o jogo de se sentir olhado por todos e ao mesmo tempo desejar esconder-se de tudo. Devido à "banalização do espaço" as pessoas se encontram em um mesmo ambiente para resolver preocupações particulares, não conversam com a multidão a sua volta. Em virtude do uso do espaço comum por muitos a cidade aos poucos deixa de ser o lado de fora das moradias. A rua recebe qualquer passante ao passeio, por isso "[...] a cidade pode abrir-se diante do transeunte como uma paisagem sem soleiras" (BENJAMIM, 1989, p.192).

Desse modo, podemos aproximar a banalização do espaço comum, a este processo de despersonalização citado por Friedrich na poética de Charles Baudelaire. Em sua poesia é possível encontrar a ausência da intimidade comunicativa. Este poeta diferentemente dos poetas românticos, conforme a esteira da crítica que estabelece apenas a subjetividade como recurso poético, busca por meio da palavra versificada questionar a sociedade na qual se insere, além de desabilitar uma leitura aos seus poemas pela via biográfica. Em linhas gerais, podemos pensar que a partir do "poeta da modernidade", o poema passa a ganhar os sintomas de crise, de reinvindicação de forma mais abrangente.

Com a finalidade de encontrar a pluralidade de significação por meio da palavra, os poetas modernos recorreram ao exercício da experimentação da linguagem. Os parâmetros para a composição do poema como: a sintaxe, a metáfora e a comparação sofrem alterações que fazem com que o leitor desconfie de uma certa anormalidade devido à ausência destas convenções de escritas e/ou estilísticas na poesia romântica. Em síntese, a pluralidade de significados relaciona-se com a tensão dissonante, já que esta dissonância é resultado de um processo maior de ruptura de significados tanto no campo religioso, filosófico e ideológico ocorrido na modernidade. Logo, a anormalidade apontada por Friedrich não é nada mais do que uma ausência de padrão estético reconhecido para explicar a poesia moderna. Se a civilização humana a partir do século XIX questiona a existência de Deus por que a linguagem sairia incólume desta batalha?

A crise do sujeito iniciada pelos românticos alemães de alguma maneira, desemboca na conjuntura da sociedade moderna e consequentemente na contemporânea. $\mathrm{O}$ termo contemporâneo arrasta para si uma avalanche de questionamentos insolúveis, tornando a sua própria definição problemática. Sucessivamente, vários teóricos tentaram definir este período de tempo intitulado como contemporâneo, entretanto esta é uma discussão que permanece em aberto. Como podemos delimitar a literatura em prosa e em verso hoje? A partir de que década consideramos a lírica aqui estudada como contemporânea? Com o objetivo de tornar nossa discussão mais produtiva delimitaremos como contemporâneo a 
literatura produzida a partir dos anos $00^{3}$. No texto $\mathbf{O}$ que é contemporâneo? Karl Erik Schollhammer procura situar a problemática conceituação deste termo a partir de leitura a Giorgio Agambem que o define a partir de Nietsche, o contemporâneo como intempestivo. No sentido, em que é impossível de defini-lo plenamente. Segundo Schollhammer (2009),

O contemporâneo é aquele que, graças a uma diferença uma defasagem ou um anacronismo, é capaz de captar seu tempo enxergá-lo. Por não se identificar, por sentir-se em desconexão com o presente, cria um ângulo do qual é possível expressá-lo. Assim a literatura contemporânea não será necessariamente aquela que representa a atualidade, a não ser por uma inadequação, uma estranheza histórica que faz perceber as zonas marginais e obscuras do presente, que se afastam de sua lógica. (SCHOLLHAMMER,2009, p.9)

Portanto, entenderemos contemporâneo como um movimento que, por estar em constante processo de tornar-se, apresenta como característica principal a parcialidade de significado, ou seja, capturar todos os contornos desta vertente da literatura é uma tarefa hercúlea, assim como, alcançar todas as possibilidades de leitura de qualquer poema. Definir a geração de poetas surgidos no século XXI, não é nosso objetivo. Entretanto, postergar a definição não afugenta uma discussão crítica acerca deste assunto. Assim, nosso estudo tentará esboçar de forma breve algumas tendências desta lírica contemporânea nos versos de Rui Torres, poeta português, e Ângela Vilma, poetisa baiana. Em que medida, autores com sensibilidades poéticas diferenciadas se apresentam na literatura contemporânea.

\section{A LÍRICA CONTEMPORÂNEA NOS VERSOS DE ÂNGELA VILMA E RUI TORRES}

O poeta Rui Torres ${ }^{4}$, se insere na lírica contemporânea através do largo uso da técnica presente na era digital, como o uso de imagens que se formam na tela ao clicar em uma palavra, nas letras em flash que necessitam de uma postura diferente frente ao texto, por parte do leitor, uso de símbolos emprestados da computação gráfica, por exemplo. A sua realização lírica permite a ruptura com o modelo tradicional (século XIX) de leitor, poeta, poema, ao mesmo tempo em que, recupera em alguma medida, uma tradição literária, como a promovida pelos poetas do Movimento Concretista no século XX. Para efeito de discussão, é importante examinar as duas tendências, o uso da técnica e da tradição, presentes na lírica de Rui Torres.

\footnotetext{
${ }^{3}$ Termo empregado pelo teórico Karl Erik Schollhammer(2008) para definir a geração de escritores brasileiros a partir dos anos 2000 .

${ }^{4}$ Licenciado em Ciências da Comunicação (UFP, Porto), M.A. e Ph.D. em Literatura luso-brasileira (UNCChapel Hill, E.U.A.), Pós-doutoramento como Bolseiro da Fundação para a Ciência e a Tecnologia (COS PUC/SP, Brasil) Agregação em Ciências da Informação - Estudos Multimediáticos (UFP, Porto). Investigador da Unidade I\&D FP2S (UFP) e do Centro de Comunicação Digital e Pesquisa Partilhada (ECA, USP, Brasil). Membro do Board of Directors da Electronic Literature Organization.
} 
No texto A nova analogia: poesia e tecnologia Octavio Paz (2012) desenvolve uma argumentação acerca da relação entre a poesia e os novos recursos técnicos como computador, televisão e rádio. Para ele, quando um poeta recorre ao uso do computador para a elaboração do poema, não está anulando-se, mas fazendo uso de uma técnica similar ao processo de criação humana. A técnica apresenta-se como função, não como significado para este teórico. Ao fazer uso do aparato tecnológico o artista ainda é o elemento primordial para a realização lírica, pois é por sua vontade que as engrenagens que constituem o poema são escolhidas, sejam elas audiovisuais, digitais ou escritas. Neste sentido, a técnica apresenta-se como um instrumento crítico, pois possibilita pensar: o que é o poema? Nas palavras de Paz (2012),

[...] a técnica muda a poesia e a mudará cada vez mais. Não poderia ser diferente: sua intervenção afeta tanto a transmissão e a recepção de poemas como os métodos para compôlos. Mas essas mudanças, por mais profundas que nos pareçam, não a desnaturam. Ao contrário, devolvem-na à sua origem, ao que ela era a princípio: palavra falada, compartilhada por um grupo." (PAZ,2012, p. .327)

As composições de Rui Torres, em particular o poema intitulado "PoemAds - Sob o signo da devoração" "5apresenta a união da técnica na elaboração poética, por parte do poeta, e ecos com a poesia concreta, largamente sedimentada nos manuais de teoria literária. O poeta retoma a relação existente entre a imagem e a palavra, como também, reconhece a contribuição dos movimentos literários de vanguarda em sua produção. Podemos exemplificar, este reconhecimento na alusão no subtítulo, do poema em destaque, ao movimento modernista desenvolvido no Brasil em 1922.

Podemos aproximar a poética de Rui torres, aos argumentos que Marjorie Perloff (2013) desenvolve em seu texto: O gênio não original: uma introdução. Esta teórica aponta algumas características da produção poética a partir de meados do século XX que continuam de alguma forma reverberando na produção século XXI. Como por exemplo, a distorção sintática, citacionalidade, apropriação de outros textos, uso extensivo de palavras e/ou frases de língua estrangeira. O "PoemAds - Sob o signo da devoração", torna-se representante da poética digital produzida neste início século. A tensão promovida entre os elementos que o constituem apresenta-se como característica fundamental para a sua existência.

Ao isolarmos apenas uma característica contida neste poema citado, a citacionalidade perceberemos como apesar de conter frases que são próprias de slogans de produtos diversos, o poema garante ao leitor sentido, ao mesmo tempo que ironiza todas as convenções de elaboração de um poema impresso,seja ele de vanguarda ou tradicional. A recorrência das citações de segunda mão, torna-se o vigor do texto e não mero apêndice. Conforme Marjorie Perloff (2013),

[...]O uso do texto apropriado de outros autores, incluindo material de arquivo, documentários, manuais de informação e, recentemente, de discurso da internet, do

\footnotetext{
${ }^{5}$ Poema disponível em: < http://www.telepoesis.net/poemads/>. Acesso em: 30 set. 2015. Esta produção para ser lida de forma mais satisfatória, necessita do recurso da internet,
} 
hipertexto ao blog ao banco de dados, a citacionalidade - com sua dialética de remoção e enxerto, disjunção e conjunção, sua interpenetração de origem e destruição- é central para a poética do século 21. (PERLOFF, 2013, p.48)

Como assinala Lucia Santaella (2011), o aperfeiçoamento digital favoreceu a "convergência das mídias". Os quatro principais meios de comunicação humana foram reunidos em um mesmo campo, como por exemplo, o texto escrito, o som e a imagem, o telefone e a informática. Tornando possível, o acesso rápido e a reprodução com baixos custos. Assim, "[...] Antes da digitalização, os suportes das diferentes linguagens eram incompatíveis: papel para o texto, película química para a fotografia ou filme, fita magnética para o som ou vídeo. Atualmente, a transmissão da informação digital é independente do meio de transporte (fio do telefone, onda de rádio, satélite de televisão, cabo etc.)." (SANTAELLA, 2011, p.3).

O uso do procedimento tecnológico, a partir dos anos 2000, no século XXI, ganhou proporções mais amplas com a utilização das novas tecnologias para a publicação e elaboração literária tanto em prosa como em versos. Embora, haja um volume de estudos centrados no texto em prosa, podemos perceber através destes poetas, aqui em estudo, como as novas tecnologias possibilitaram tornar seu fazer literário mais visibilizado. É neste quesito, que a poetisa Ângela Vilma se aproxima de Rui Torres na lírica contemporânea.

Enquanto, Rui Torres se alimenta do fazer literário produzido pelos concretistas e exercita ao máximo a relação entre a poesia e a técnica digital, Ângela Vilma faz uso comedido das novas tecnologias, utilizando apenas a ferramenta do blog para a publicação de seus textos. Mas, assim como o português, retoma, em alguma medida, um fazer literário precedente. É evidente, que os poemas produzidos por Rui Torres se distanciam da produção da poetisa, devido a vários elementos. Entretanto, esta é uma característica da lírica contemporânea, promover o convívio de diferentes tendências que ora seguem a concepção de lírico secular, ora divergem desta concepção.

Em linhas gerais, ao analisar os poemas postados no blog Aeronauta da escritora Ângela Vilma, durante o ano de 2012 é possível perceber como a realização lírica desta poetisa aproxima-se de uma concepção de lírica formulado pelos românticos, e teorizado posteriormente por Hegel. Seus poemas evocam a constância da referencialidade na primeira pessoa do discurso, logo da subjetividade, mesmo que esta subjetividade não possa ser mais, nesta época contemporânea, entendida como produto de uma sinceridade transparente como outrora. Ao contrário de Rui Torres, ela utiliza-se da linguagem de outros por meio da intertextualidade e não citacionalidade em seus poemas. Evidenciando assim, como a lírica contemporânea busca, também, tornar possível para leitor o reencontro de sua subjetividade e da imagem do mundo diante da leitura de poesia sem buscar encontrar desesperadamente a inovação, o novo.

\section{CONSIDERAÇÕES FINAIS}

Diante do exposto, podemos pensar como poema abriga em sua constituição heranças provindas tanto das cantigas declamadas pelos gregos em praças públicas, tanto 
dos românticos que imprimiram a expressão íntima em suas composições, ou dos modernos que romperam com os modelos estéticos já institucionalizados. Em suma, concluímos que a realização lírica em diferentes épocas se apresentou com diversas facetas para o leitor e para crítica. Octavio Paz nos afirma: “[...] Em perpétua mudança, a poesia não avança" (2012, p. 312), desta forma o caminho percorrido pelos versos jamais pode ser considerado como um movimento linear, com início, meio e fim. A lírica moderna e a lírica contemporânea possuem pontos de interseção e de afastamento, que são provocados pela tensão constante do verbo transformar, que conserva e, ao mesmo tempo, pode dissipar qualquer fundamento. Assim, a poesia sempre foi contemporânea, no sentido que perseverou na busca do insólito.

\section{REFERÊNCIAS}

ANDRADE, Carlos Drummond de. José/Novos poemas/Fazendeiro do ar. 5. ed. Rio de Janeiro: Record,1998. p.73-101.

BRAGA FILHO, Jair Ramos. O autor moderno e o pintor romântico: Charles Baudelaire e Eugène Delacroix. 2006. 40f. TCC- Setor de Ciências Humanas, Letras e Artes, Universidade Federal do Paraná, Curitiba, 2006. Disponível em: < http://www.letras.ufpr.br/documentos/graduacao/monografias/ss_2006/Jair_Braga_F iho.pdf $>$ acesso em: 5 jan.2015.

BENJAMIM, Walter. O Flâneur. In: idem. Charles Baudelaire: um lírico no auge do capitalismo. São Paulo: Brasiliense, 1989.p.185-236.

CARA, Salete de Almeida. A Poesia Lírica. São Paulo: Ática, 1989

COMBE, D. A referência desdobrada. O sujeito lírico entre a ficção e a autobiografia. Revista USP, 84, 2009-2010, p. 112-128. Disponível em: < http://www.revistas.usp.br/revusp/article/view/13790/15608> Acesso em: 08 jan.2015

D’ONOFRIO, Salvatore. Teoria do Texto 2 - teoria da lírica e do drama. São Paulo: Ática, 1995.

FRIDERICH, Hugo. Perspectiva da lírica contemporânea: dissonâncias e anormalidade. In: Estrutura da lírica moderna (da metade do século XIX a meados do século XX) São Paulo: Duas cidades.1978. p.15-34.

FRIDERICH, Hugo. Baudelaire. In: . Estrutura da lírica moderna (da metade do século XIX a meados do século XX) São Paulo: Duas cidades.1978. p.35-58.

GIDDENS, Anthony. As consequências da modernidade. Trad. de Raul Fiker. São Paulo: Editora UNESP, 1991.p.8-15.

HAMBURGER, Michael. A verdade da poesia.in: A verdade da poesia: tensões na poesia modernista desde Baudelaire. Trad. Alípio Correia de franca neto. São Paulo: Cosac Naify, 2007. p. 35-61. 
HEISE, Eloá; RÖHL, Ruth. O Romantismo. In: História da literatura alemã. São Paulo:Ática.1986.p.42-55 (série princípios)

HEISE, Eloá; RÖHL, Ruth. Sturm und Drang. In: História da literatura alemã. São Paulo:Ática.1986.p.26-31 (série princípios)

PAZ, Octavio. O arco e a lira.2 ed. Trad. Ari Roitman e Paulina Wacht. São Paulo: CosacNaify, 2012.p.312.

. A nova analogia: poesia e tecnologia.In: O arco e a lira.2 ed. Trad. Ari Roitman e Paulina Wacht. São Paulo: Cosac Naify, 2012.p.319-338.

Os signos em rotação. In: . O arco e a lira. 2 ed. Trad. Ari Roitman e Paulina Wacht. São Paulo: Cosac Naify, 2012.p.259-291.

PERLOFF, Marjorie. O gênio não original: uma introdução. In: O gênio não original: poesia por outros meios no novo século. Trad. Adriano Scandolara. Belo horizonte: UFMG, 2013. p.

PERLOFF, Marjorie. Da vanguarda a digital: o legado da poesia concreta brasileira. In: - O gênio não original: poesia por outros meios no novo século. Trad. Adriano Scandolara. Belo horizonte: UFMG, 2013. p.95-133.

RESENDE, Beatriz. Literatura sem papel: a virtualidade poética de Maira Paula e o folhetim eletrônico de Ana Paula Maia. In. Contemporâneos: expressões da literatura brasileira no século XXI. Rio de janeiro: Casa da Palavra: Biblioteca Nacional, 2008.p.135-144.

ROCHA, Roosevelt. Lírica Grega Arcaica e Lírica Moderna: Uma Comparação. Philia\&Filia, Porto Alegre, vol. 03, n 2, p. 84-97, jul./dez. 2012. Disponível em: $<$ http://seer.ufrgs.br/index.php/Philiaefilia/article/view/37252/24081. Acesso em: 5 jan.2015.

ROSENTHAL, Erwin Theodor. O movimento pré-romântico. In: . $A$ literatura alemã. São Paulo: USP,1960. p.55-83.

SANTAELLA, Lucia. Transmutações da escrita em suporte digital. In: III ENCONTRO INTERNACIONAL DE ESTUDOS DA LINGUAGEM, Pouso alegre, 15 a 17 de setembro de 2011, Anais do Enelin 2011. Pouso alegre: Univás, 2011, p.1-9. Disponível em: www.cienciasdalinguagem.net/enelin. Acesso em: 27 Abr. 2014

SCHOLLHAMMER, Karl Erik. O que é contemporâneo? In: . Ficção brasileira contemporânea. Rio de Janeiro: Civilização Brasileira, 2009. p. 9-52 